\title{
Toward A Mentoring Model For Promotion And Tenure: Progress And Pitfalls
}

\author{
Irene M. Duranczyk, University of Minnesota, Twin Cities, USA \\ Na'im Madyun, University of Minnesota, Twin Cities, USA \\ Rashné R. Jehangir, University of Minnesota, Twin Cities, USA \\ Jeanne L. Higbee, University of Minnesota, Twin Cities, USA
}

\begin{abstract}
This article provides a qualitative analysis of a pretenure mentoring model that was designed to enhance the likelihood of retaining diverse faculty recruited for a multidisciplinary undergraduate department. The data capture the experiences of pretenure and tenured faculty after the first 4 years of the implementation of this mentoring system. The mentoring system and data collection process are described, followed by the research findings and implications for practice.
\end{abstract}

Keywords: tenure; faculty mentoring; diversity

\section{INTRODUCTION}

Te have heard the postsecondary promotion and tenure process likened to fraternity and sorority hazing, in which a group of more experienced peers have the power to admit or deny access to their elite organization based on a set of criteria that are at best often unclear, and at their worst seemingly inconsistent, favoring people of some social identities over others. The advantages that sorority and fraternity pledges have over pretenure faculty are that their pledge period lasts less than a year, they do not have to leave the college or university if they are not inducted into the Greek system, their livelihood and the well being of any dependents are not tied to a single vote, and they do not have to go through a similar process again 5 to 10 years later. This article describes the steps that the faculty in the Department of Postsecondary Teaching and Learning (PsTL) at the University of Minnesota took to try to demystify the tenure and promotion process to ensure equitable opportunities for success for all pretenure faculty members, and the evaluation of the new model in fall 2010.

\section{Background}

In 1999 the General College (GC; Higbee, Lundell, \& Arendale, 2005) at the University of Minnesota hired a new cohort of faculty that included one tenured associate professor and seven assistant professors. Of the seven, five are male and two are female and three are Faculty of Color. On June 30, 2006 GC was closed and its diverse faculty (both from the perspective of social identities and in terms of academic disciplines represented) found a new home as the Department of Postsecondary Teaching and Learning (PsTL) in the University's College of Education and Human Development. Between 2001 and 2010 an additional 13 assistant professors were hired in GC/PsTL; of these, 6 are male and 7 are female. In addition to gender diversity, 7 are also Faculty of Color. Despite both local and national concerns about the pool of available applicants, in the last decade GC/PsTL has been very successful in recruiting faculty who are female and/or Persons of Color with backgrounds to teach courses in mathematics, statistics, symbolic logic, and geology, among other disciplines. Of these 20 assistant professors, 13 are now tenured and still teaching at the University of Minnesota, although some are now in other departments. One of these faculty members is now an associate dean in CEHD, one is the department chair for PsTL, and one is the department chair for African American Studies. Two assistant professors are going up for tenure in the 2011-2012 academic year, and one will most likely seek tenure in 2013-2014. Meanwhile, of the 20 assistant professors who were recruited and hired by GC/PsTL from 1999 to the present, 1 was denied tenure (not a Person of Color) and 3 chose to leave prior to seeking tenure; all 3 are Faculty of Color. 
Figure 1. Policy Statement Related to New Mentoring Process

NEW COMPONENT: Review and Promotion Committee

1. Composition of the Committee: Two Associate Professors or Professors will be assigned to each pretenure faculty member. The committee will be selected by the chair based on consultation with the pretenure faculty member as well as with potential committee members.

2. Purpose of Committee: The purpose of this committee is to distribute accountability and responsibility for the review and tenure process by engaging tenured faculty directly in this work beyond the annual review of the candidate's "boxes." (See Note) Additionally, this committee will enable us to review candidates more efficiently and effectively with the purpose of providing constructive feedback over the pretenure period.

3. Responsibilities: For purposes of annual review, the committee will be responsible for presenting the candidate's case to the voting faculty. While all voting faculty members are responsible for reading and assessing the candidate's progress, the committee will give a short (3-5 minute) overview to the voting faculty on:

- the progress and contributions made in teaching, research, and service in the past year, with attention to focus, impact and significance of work within these areas;

- $\quad$ the strengths and weakness of the case as it has developed to date;

- $\quad$ suggestions for building on existing strengths; recommendations for addressing gaps or weaknesses.

For the purposes of the tenure and promotion review, the committee will write the "unit report" described in the University's "Procedures for Reviewing Candidates for Tenure and/or Promotion." The chair will work with the tenure candidate to assemble the required materials and to complete the candidate's dossier. Once the dossier is complete, the committee will work in consultation with the chair to draft the Unit Report, the summary and appraisal of research, teaching, and service during the probation period, drawing on specific examples and evidence from the dossier, and summarizing the departmental process. The chair will be responsible for the Chair's report (referred to in the "Procedures" document) as well as for reporting on the results of the decision meeting.

Note: The candidate's box is the physical organizing file each pretenure faculty member uses to compile materials for review by all tenured faculty members in the department. The box of hanging files is typically divided into four sections: introduction, research, teaching, and service. The introduction section includes a table of contents for the box as a whole, the faculty tenure and promotion policy, the candidate's curriculum vitae, and summaries of each annual review. The research section includes a research statement, published manuscripts, grant submissions, and evidence of scholarly impact. The teaching section includes a teaching statement, course evaluations, peer observations of teaching, and relevant syllabi. The service section includes a service statement, evidence of committee work at various levels inside and outside the university, service to the profession, and work-related community service.

Although to some extent the decision to leave for two of the faculty members may have been prompted by the closing of GC and its accompanying uncertainty regarding the climate and tenure expectations in the resulting new college, the fact remains that all White faculty hires were retained through the pretenure period and some Faculty of Color were not.

At the critical juncture when GC was in the process of closing, members of a new cohort of Faculty of Color were just beginning their positions on the tenure track in the new department. Previously in GC, no formal model for mentoring existed; it was up to individual faculty - both tenured and pretenure - to initiate informal mentoring relationships. Thus, some faculty received extensive mentoring-whether appropriate and helpful or not - and others received little or no mentoring.

\section{Development of a New Mentoring Model}

In winter 2007, a working group of PsTL faculty was charged with developing a model for mentoring and pretenure review to facilitate the retention and successful promotion to tenured associate professor for all pretenure faculty members. The basic assumption of the working group was that new faculty members were hired because of the many contributions they could make and the department should be heavily invested in ensuring their success. This assumption is reflected in the new name pretenure rather than tenure-track. The working group vetted its proposal through both open meetings with pretenure faculty and also opportunities for faculty to respond in writing. The model that resulted has now been in operation for several years. In fall 2009, the model was expanded to include mentoring for promotion from associate to full professor. Figure 1 presents the policy that governs the new model. 


\section{METHOD}

In September 2010, PsTL conducted an online survey of all PsTL tenured and tenure-track faculty members. Survey items were individually generated depending upon faculty responses to the following demographic markers:

- $\quad$ Assistant professor
- $\quad$ Associate professor
- $\quad$ Now tenured, and received mentoring under the current system prior to tenure and promotion
- $\quad$ Currently serve or have served as a mentor within the new system

Figures 2 through 7 list the survey questions each faculty group received.

\section{Response Rate}

The Assessment of the Pretenure Mentoring Model survey was sent out to 25 faculty (20 current PsTL faculty, 2 recent retirees, and 3 faculty who were tenured in 2004-2005 but left the department before the implementation of the mentor system). There was a $70 \%$ response rate among current faculty and an overall response rate of $68 \%$. Responses were more likely to come from the assistant professor pool (100\%) rather than the associate professor (64\%) or full professor (75\%) pools. Among the associate professors, those who were mentored under the current model were much more likely to respond to the survey than those who were not. Overall, there was also only a 59\% response rate among current or past mentors.

\section{Limitations}

It should be noted that one limitation of this research is that the authors were participants in the study. The small size of the department and the importance of our individual demographics were two significant factors in our decision to remain in the sample. As previously stated, there are 20 current faculty members. One of the authors is the only female full professor and has served as a mentor to four of the recent hires, two of the authors are Faculty of Color, and three of the authors have been mentored through the system. Therefore, we believed it was important that our voices be included. Another limitation is that some respondents did not check all the demographic markers that might have applied to them. Even though there are rich data from this survey, we are fully aware that there is more to know. The following paragraphs provide the results of the data analysis.

\section{RESULTS}

The results were codified and analyzed by all four authors, who then met twice to discuss their interpretations. The presentation of the results is organized by the demographic markers that determined which faculty members responded to specific items.

\section{Items for All Faculty Members}

There were seven questions that all faculty members surveyed were requested to complete (Figure 2). These questions were generated irrespective of the demographic markers each faculty member selected.

\section{Development of the model.}

Despite a range of responses, there were some consistent themes that emerged across categories of tenured (full and associate) and pretenure (assistant) professors. From a macro and organizational structure perspective, many respondents noted that a shift from being a stand-alone college to becoming a department in a new college required a "more systematic and shared faculty model of mentoring that is not so dependent on the work of the dept. head." Others noted that investing in tenure-track faculty (TTF) through the implementation of a model that would 
provide assistance navigating the tenure process was not only something that is reflected in the literature (Greene, O'Connor, Good, Ledford, Peel, \& Zhang, 2008; Thompson, 2008; Trowler, 2009), but was also an expressed preference of the TTF, who considered a navigational model through tenure as an unmet need. Without such a model in place, the tenure process had been difficult for many and humiliating for several. A review of the survey data indicated that in general faculty consider the model helpful in providing guidance to assistant professors and ensuring that there are senior faculty who know the tenure candidates' cases well.

Figure 2. Assessment of the Pretenure Mentoring Model Survey Questions: All Faculty

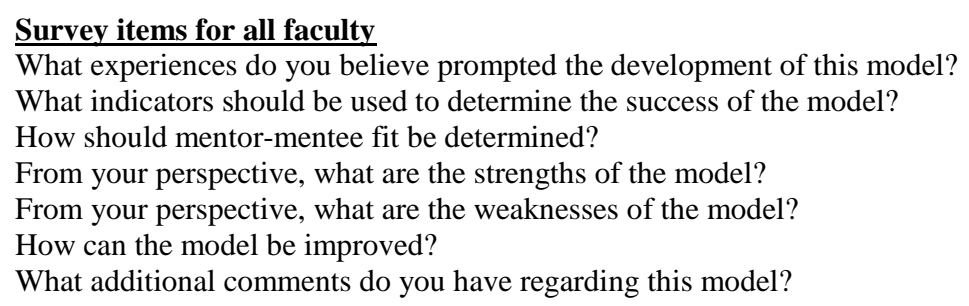

\section{Determining model success.}

Regarding responses about indicators of success of this current model, two general themes emerged. The first pertains to the extent to which tenure-track faculty perceived or experienced satisfaction with their process toward tenure as well as the extent to which mentors felt satisfied with their role in the process. The second theme included arguments about looking at the number of mentored faculty who were tenured under this model. Respondents noted that while mentoring alone cannot guarantee tenure and that some may indeed get tenure regardless of the model, it is important to examine the process by which tenure is achieved with consideration of support, clear expectations, and mentoring that extends beyond preparing one's box as indicators of the model's success.

\section{Determining mentor-mentee fit.}

The respondents suggested a shared process whereby mentees would have "primary input" and select from a list of potential mentors and then mentors would be appointed in consultation with the chair of the department. Other considerations included disciplinary and relational matches between mentor and mentee.

\section{Strengths of the model.}

Providing a process and space for informed representation was the most notable strength of the model identified by faculty. The faculty valued not just being informed, but the quality of the information provided by mentors. Respondents commented that the information was fair, objective, and appeared to be constructed more from a team than just one voice or agenda. Full professors noted how the representation improved annual review meetings. Messages were clearer, less diluted, and more likely to prevent individual biases from controlling the discourse. Another identified strength of the model was an apparent demystification of the process. Interestingly, associate and assistant professors identified this as a strength for different reasons. Associate professors were more likely than other faculty to note the opportunity to give early and continuous feedback. Assistant professors believed that the model gave them more control over both how they would be represented at review meetings and how to tailor their experiences to increase the likelihood of positive feedback. Although mentioned by other faculty, assistant professors were more likely to identify the opportunity to work closely with tenured faculty as a strength. Finally, it was noted that the new model resulted in shared governance, with the department chair still playing an important role but others involved in presenting the tenure case as well. 
Model weaknesses.

A major weakness of the model was the variability in mentor "quality." Some senior faculty appeared to take the responsibility more seriously than others. Assistant professors stated that the requirements for mentoring appeared to be loose and that mentors' advocacy on behalf of the mentee can be too influential as a determining factor of success. Contributing to variability in mentor quality was perhaps the absence of a common definition and application of mentoring as noted by several respondents. The absence of such a foundational component places more stress on mentor-mentee fit. From the assistant professor group, the question of whether mentors are merely functioning in an advising role and not actually working to groom their mentees was raised by multiple respondents.

Another identified weakness of the model was the mentor having to walk a fine line between stating the facts of the mentee's case and functioning as an advocate. It was noted among the mentor group that there was a concern over the possible consequences for the mentor if the mentee did not achieve tenure. A particularly interesting weakness that may result from a strength of the model was the possibility of an increase in "social loafing" and "group think." It was stated that some tenured faculty members may reduce their amount of effort in reviewing the tenure boxes with the knowledge that the mentors would do both a thorough review and presentation. Having mentors present the tenure cases may also reduce the level of critique by pushing tenured faculty to overly rely on the mentors' interpretations. It should be noted, however, that several tenured faculty thought that the model did not have any noticeable weaknesses.

Improving the model.

Given the identified strengths and weaknesses of the model, faculty recommended three main ways to improve the model. The first recommendation was to develop a formal orientation and training for all faculty in order to address misunderstandings, agree upon best practices, and to close the gap between expectations and experiences. The second recommendation was to improve the quality of the meetings between mentor and mentee by establishing minimum guidelines for frequency and content. The third recommendation was to increase the pool of potential mentors by including nonvoting faculty as possibilities (e.g., tenured faculty from outside PsTL).

\section{Items for Mentees and Mentors Under the Current System}

This section of the survey was designed for faculty who participated in the new system either as mentees or mentors. Figure 3 lists the specific questions asked of this group.

Figure 3. Assessment of the Pretenure Mentoring Model Survey Questions: Faculty Who Have Been a Mentor or Mentee

\section{Survey items for faculty who have been a mentee and/or a mentor:}

What do you consider the primary responsibilities of the mentor?

What training should be provided for mentors?

What (if any) unanticipated benefits have you reaped from your participation as a mentor or mentee?

Has the model changed how you feel about the tenure process? Why or why not?

\section{Primary responsibilities of the mentor.}

Many of the mentors believed that their main responsibilities included developing a consistent relationship with their mentee that allowed for multiple areas of support. To establish the consistent relationship, mentors identified the importance of understanding both the professional goals of the mentee and the goals of the mentoring relationship. Once the goals were identified, mentors felt responsible for creating measurable objectives along a tenure timeline and meeting regularly with their mentee to ensure progress. After creating the framework for the relationship, mentors considered it their responsibility to utilize that framework to be as supportive as possible to the mentee by being appropriately proactive and reactive. This included being a resource that identified relevant publication venues, reviewing manuscript drafts, providing feedback on tenure statements, offering strategic service options, and adapting to departmental concerns regarding the mentee's tenure case. One tenured faculty member 
who received mentoring under the new system near the end of the tenure process suggested, "Do not sugar coat the process. Be honest and give realistic feedback on research, teaching, and service." It was noted that it is also the responsibility of the mentors to "objectively present the case to the total faculty during yearly votes and final decision" and that a mentor can "act as a liaison between the TTF and other faculty when misunderstandings arise" - which may be particularly important during reviews, when the mentors should be more knowledgeable about the case than other faculty members.

Interestingly, the mentor responsibilities identified by the mentees were quite similar to those mentioned by the mentors. These responsibilities included reviewing the candidate's progress in light of departmental standards, giving advice about publication venues, providing feedback, and offering a listening ear.

\section{Mentor training.}

In response to what training should be provided for mentors, ideas included a review of the responsibilities of the mentor; clarification of the tenure code including departmental, college, and university regulations and processes; and reading the research statements of successful candidates with the intent to provide feedback for the mentees. A mentor noted that training should include a discussion of "where to draw the line in terms of expectations on both sides of this relationship." One associate professor who received mentoring under the new system wrote, "Have the attitude that your mentee is worthy of tenure rather than the attitude that tenure is only for the "chosen few'."

\section{Unanticipated benefits of the model.}

In terms of unanticipated benefits, both mentors and mentees acknowledged the opportunity to develop deeper relationships with colleagues. A mentee who has earned tenure and promotion replied, "I have someone who can continue to support my professional journey to full professor."

\section{Impact on feelings about the tenure process.}

Both mentors and mentees stated that the new model changed how they currently feel about the tenure and promotion process. One of the mentees expressed a feeling of "being set up to fail" in a "hostile working place" before the new system was created: "The tenure process before my mentors was HELL." One mentor commented,

I wish that a model like this had existed for me when I was an assistant professor. The tenure process is always going to be stressful — there is no way around that—but hopefully this mentoring system provides a support network. ...

The tenure process . . . could be unnecessarily cruel. This model is not the only factor in changing that, but it is one of several factors that have led to a more humane tenure process.

\section{Items for Pretenure Faculty}

Five respondents were pretenure faculty when the survey was administered. Figure 4 lists the specific questions asked of this group.

Figure 4. Assessment of the Pretenure Mentoring Model Survey Questions: All Pretenure Faculty

\section{Survey items for pretenure faculty who have been mentored under the current system:}

How did you decide upon the mentors you chose?

What are the ways in which you utilize your mentors?

What aspects of the current model have been most helpful?

What aspects of the current model have been least helpful?

What have you gained from participating in this model that you are certain you would not have if the model was not implemented?

What is the one most important piece of advice or assistance that you have received from your mentor?

How is your experience during the pretenure process developmentally preparing you for the annual reviews, "decision year" processes, and post-tenure life at the U? 


\section{Selecting a mentor.}

Four of the five respondents noted that their mentor selection was based on a match of teaching discipline or research focus and guidance from the department chair. Three of the five also noted previously established interpersonal relationships as well as attention to "those who knew my work" or had "taken an interest in me in the past."

\section{Utilizing the mentor.}

For this category, one overarching theme for most respondents was that the utilization of mentors and the mentoring experience was focused on product rather than process. For example, mentors were utilized for "organizing my case", "packaging and professionalism", and "feedback on drafts of manuscripts", and less for "how to best research" or create a broader plan toward progress to tenure.

\section{Most helpful aspects of the model.}

What mentees believed was most helpful about the model related well with their responses for how they utilized their mentors. Three of the five respondents asserted that the most helpful aspect of the model was feedback received on "organizing my box" and preparing for "annual review." Two respondents noted that "advice and encouragement" as well as feeling "comfortable" asking for assistance in a range of areas was most helpful, but noted that "this was not the case for all mentees."

\section{Least helpful aspects of the model.}

There were various critiques of the model, all of which stemmed from what appears to be a question about consistency or common benchmarks in the model that could guide the process and product creation toward tenure for both mentees and mentors. One respondent questioned if the term mentoring was appropriate, while others alluded to this concern by noting that there was "lack of relationship development between mentor and mentee." There were also concerns about the enactment of the mentor model; one respondent noted that mentors were "assigned very late in the game" for some pretenure faculty, and another questioned whether opportunities for the "mentors to meet as [a] team with the assistant faculty" would have yielded more consistent expectations and satisfying experiences.

\section{Benefits unique to this model.}

When prompting respondents to determine the value added from this model, two respondents referenced how the model provided "guidance regarding the process" and a sense of being more "savvy" about the inner workings of the tenure process. The most substantive response noted that the process invites the promotion and tenure committee to get "invested" in the candidate in ways that may not have occurred in the absence of such a model.

\section{Most important piece of advice.}

Some of the most useful advice noted by mentees centered around how to be "strategic" about time, projects, and goals, as well as thinking about how to use one's work to "display my voice when I am not in the room." In terms of the impact of the advice, mentees noted that it served to provide "hope and optimism" in the face of what appears to be a slow process to one's goals on the tenure track.

Preparatory value of the model.

Half the pretenure respondents thought the process better prepared them for the annual review and helped to familiarize them with "expectations and knowledge of the process." The other half indicated that it did very little to make smooth the process toward tenure but it did assist to "develop an understanding and appreciation for faculty politics and hazing." 


\section{Items for Tenured Faculty Who Were Mentored Under the Current System}

Because the new mentoring model has been in place for a relatively short period of time, there were two tenured respondents who were able to address questions about their experiences under both the old and new mentoring systems. Figure 5 lists the questions for this particular group of faculty. Although there were some commonalities in their responses, particularly with how they utilized mentors, their responses also suggested that progress toward tenure was vastly different for each of them. Common themes pertained to the role that mentors played in providing feedback around developing materials for the tenure case (e.g., research, teaching, and service statements), selecting external reviewers, and exploring funding sources.

Figure 5. Assessment of the Pretenure Mentoring Model Survey Questions: All Tenured Faculty Mentored Under the Current System

Survey items for tenured faculty who were mentored under the current system:
How did you decide upon the mentors you chose?
What are the ways in which you utilized your mentors?
What aspects of the current model were most helpful?
What did you gain from participating in this model that you are certain you would not have if the model was not
implemented?
What is the one most important piece of advice or assistance that you received from your mentor?
How did your experience during the pretenure process developmentally prepare you for the annual reviews, "decision year"
processes, and post-tenure life at the U?

Many aspects of the model that were most helpful for the two faculty tenured under the system were similar to current pretenure faculty. Interestingly, consistency in feedback and support in preparation for tenure was cited as most helpful by one of these respondents and least helpful for the other. With regard to whether experience during the pretenure process developmentally prepared the faculty member for the annual reviews, decision year processes, and post-tenure life at the University, there was great variance in the responses of the two faculty members in this group. One described the process as a "type of a boot camp, inhuman and abusive" and the other viewed it as "supportive and helpful", thus underscoring the inconsistency in experience for different individuals within one department.

\section{Items for Faculty Who Have Served as a Mentor Under the Current System}

Only one faculty member responded to the items in this category, presented in Figure 6. It is quite possible that failing to check all demographic markers was a factor in the low response rate. The responding faculty member noted that the time investment could vary greatly depending on "where the mentee is in the tenure process and also on the expectations of an individual mentee." This faculty member reported that the most rewarding aspects of being a mentor were "getting to know the mentee better" and "celebrating the mentee's affirmative tenure and promotion vote." The most frustrating aspects of being a mentor according to this faculty member were "trying to find time to be a good mentor when the timing of the process sometimes means that the most work arises at times when I am already swamped and stressed myself and needing to meet external deadlines for my own work."

Figure 6. Assessment of the Pretenure Mentoring Model Survey Questions: All Faculty who Were Mentors Under the Current System

Survey items for faculty who have been a mentor under the current system:

How did receiving mentoring prior to promotion and tenure prepare you to become a mentor for pretenure faculty members? What about the mentoring process has changed for you over time given your experience being mentored and now engaged in the role of mentor?

What insight(s) has this dual experience triggered? 


\title{
Items for Faculty Who Have Been Both a Mentee and a Mentor
}

There were no responses to the items within this category, most likely because some respondents failed to check all applicable demographic markers.

\section{Items for Faculty Tenured Prior to the New System Who Have Not Served as a Mentor}

Items for faculty tenured prior to the implementation of the new model are presented in Figure 7.

Figure 7. Assessment of the Pretenure Mentoring Model Survey Questions: All Faculty Tenured Prior to the Current Model who Have not Served as a Mentor

\author{
Survey items for faculty tenured prior to the implementation of the current system who have not served as a mentor \\ under the current system \\ Given that you were promoted and tenured prior to the implementation of the new mentoring model, what mentoring did you \\ receive to assist you in attaining promotion and tenure? \\ Do you believe that you would have benefited from the current system? \\ How did your experience during the pretenure process developmentally prepare you for the annual reviews, "decision year" \\ processes, and post-tenure life at the U?
}

Faculty who fit into this category expressed satisfaction with the amount of preparation and mentoring they received without a formalized mentoring model. They believed that the mentoring they had not received from within the department (or college in the case of faculty tenured prior to the close of GC) was often accessed outside the department, college, or University. A dominant opinion from this group was that the new model has little to no value added over the old model (or lack thereof). These faculty members miss the yearly promotion and tenure talks given by assistant professors prior to the close of GC, suggesting that those tenure talks functioned to elicit feedback and mentoring similar to the current model, but with a wider pool of potential mentors. Evident in the responses was a sense that the support received prior to the new model was more than sufficient.

\section{CONCLUSION}

The process of evaluating this mentoring model has enriched our understanding of this mentoring system and has led to many stimulating conversations with our colleagues both on campus and across the country. A mentoring system does not guarantee success but is designed to facilitate supports through the tenure process. There are still challenges in finding a good mentor-mentee fit. There is still a tension for pretenure faculty members in being comfortable confiding weaknesses or fears to their mentors and establishing their ground as confident, accomplished colleagues. It is difficult to ask for help when the process expects excellence. It is a trust walk. A mentoring system will not resolve the inherent conflicts in the tenure system, but through dialogue and periodic systematic evaluations involving all the stakeholders progress can be made. This is an initial evaluation of a mentoring system for pretenure faculty. Ongoing reviews will reveal if this process reduces the "hazing" and assists in growing diversity to enrich the academy.

\section{AUTHOR INFORMATION}

Irene M. Duranczyk is an associate professor in in the Department of Postsecondary Teaching and Learning (PsTL) and holds an EdD in Educational Leadership from Grambling State University, LA. She began as a firstgeneration college student, then the first member in the family to receive a terminal degree, and now the first to become a tenured faculty member. She was mentored in the new system. Although her research focus is access and equity in undergraduate mathematics teaching, this project is a personal passion. Irene has 20 years of experience as an administrator in postsecondary education and 15 additional years as a teacher of mathematics at the postsecondary level. E-mail: duran026@umn.edu 
Na'im Madyun is an assistant professor in the Department of Postsecondary Teaching and Learning in the College of Education and Human Development at the University of Minnesota. His research aims to inform viable solutions that address educational disparities in achievement, particularly for African Americans. E-mail: madyu002@umn.edu

Rashné R. Jehangir is an assistant professor in the Department of Postsecondary Teaching and Learning in the College of Education and Human Development at the University of Minnesota. Her research examines the experience of low-income, first-generation students in college. In particular, she focuses on how curricular and pedagogical interventions delivered in the first year impact students' longitudinal intrapersonal, interpersonal, and cognitive development. E-mail: jehan001@umn.edu

Jeanne L. Higbee has worked in higher education since 1974, first in student affairs, and since 1985 in faculty positions. She currently serves as Professor and Director of Graduate Studies for the Department of Postsecondary Teaching and Learning at the University of Minnesota, Twin Cities. She has edited or co-edited 4 books and 17 monographs and has authored more than 100 articles related to student success in higher education. E-mail: higbe002@umn.edu

\section{REFERENCES}

1. Greene, H. C., O’Connor, K. A., Good, A. J., Ledford, C. C., Peel, B. B., \& Zhang, G. (2008). Building a support system toward tenure: Challenges and needs of tenure-track faculty in colleges of education. Mentoring \& Tutoring: Partnership in Learning, 16(4), 429-447. doi:10.1080/13611260802433791

2. Higbee, J. L., Lundell, D. B., \& Arendale, D. R. (Eds.). (2005). The General College vision: Integrating intellectual growth, multicultural perspectives, and student development. Minneapolis, MN: University of Minnesota, General College, Center for Research on Developmental Education and Urban Literacy. Retrieved from: http://www.cehd.umn.edu/CRDEUL/books-thegcvision.html

3. Thompson, C. (2008). Recruitment, retention, and mentoring faculty of color: The chronicle continues. New Directions for Higher Education, 143, 47-54. Retrieved from EBSCOhost.

4. Trower, C. A. (2009). Toward a greater understanding of the tenure track for minorities. Change, 41(5), 3845. Retrieved from EBSCOhost. 